\title{
Grounded Theory Study of Conflicts in Norwegian Agile Software Projects: The Project Managers’ Perspective
}

\author{
Lubna Siddique ${ }^{1}$ and Bassam A. Hussein ${ }^{2}$ \\ ${ }^{1} \mathrm{PhD}$ Student, Department of Informatics, University of Oslo, Norway, lubnas@ifi.ui.no (corresponding author). \\ ${ }^{2}$ Bassam. A. Hussein, Associate Professor, Department of Production and Quality Engineering, Norwegian University of \\ Science and Technology Trondheim, Norway, E-mail: bassam.hussein@ntnu.no
}

Project Management

Received May 15, 2016; received revision July 2, 2016; accepted July 5, 2016

Available online July 14, 2016

\begin{abstract}
This paper aims to explore the process of conflicts in agile software projects. The purpose was to investigate the causes and consequences of these conflicts. For this purpose, we conducted a qualitative study involving agile software projects in Norway. Grounded theory was used to analyze the data and the interview findings are presented using Glaser's Six C model (context, condition, causes, consequences, contingencies, and covariance). The research findings suggest that there are several causes of conflicts. These include: the role of the product owner, an inexperienced project manager, the customer's lack of knowledge about methodology organizational hierarchy in public companies, contracting, personal egos, financial issues, not getting the right team. Consequences of conflicts include: decreased productivity, wastage of time and resources, diverted attention from project objectives loss of motivation, poor decision making, loss of communication. Based on interview data, different conflict strategies are suggested and these include appropriately skilled project manager, communication and negotiation, defining clear roles, stakeholder analysis, managing stakeholder's expectations, discussion, finding the root cause of conflict. Project managers are using these strategies to avoid or resolve conflicts. The competencies required to handle these kind of conflicts are also discussed in the paper, while the implications of theory and practice of conflict management theory are also presented.
\end{abstract}

Keywords: Agile methods, Grounded theory, conflicts, project manager, product owner.

\section{Introduction}

The Cambridge dictionary defines conflict as "an active disagreement between people with opposing opinions or principles." It is "the process which begins when one party perceives the other is frustrated or is about to frustrate some concern..." (Thomas, 1992, p. 891). Processes which there are exchanges of feedback, explanations and clarifications between different individuals may be conflicting (Zaheer, McEvily, and Perrone, 1998). Conflict could be of following types (Jehn and Bendersky, 2003).

1. Relationship conflicts "involve disagreements among group members about interpersonal issues, such as personality differences or differences in norms and values” (de Wit et al., 2012). Relationship conflict arises due to interpersonal incompatibilities or due to tension, animosity or annoyance. Relationship conflict is also called emotional conflict (Bradford and Weitz, 2009; Jehn, 1995).

2. Task conflict is differences in ideas, viewpoints and opinions relating to tasks (Reid et al., 2004). Task conflict is also known as cognitive conflict (Bradford and Weitz, 2009).
3. Process conflicts are "disagreements among group members about the logistics of task accomplishment, such as the delegation of tasks and responsibilities" (de Wit et al., 2012).

In this study, when we use term agile projects we are referring to software projects which use agile methods. When we use the term agile teams we are referring to teams which are working with agile projects. The most commonly used agile methods are the Dynamic Systems Development Method (DSDM), Extreme Programming (XP), Scrum, Lean or Kanban (Cohen et al., 2004). Throughout this paper we will be using causes of conflicts and reasons for conflicts interchangeably.

Reasons for conflicts can be differences in opinions and goals (Barki and Hartwick, 1994). In agile projects, there are more chances of conflicts occurrence (Walczak and Kuchta, 2013). According to Walczak and Kuchta (2013), "the probability and impact of conflict between team members are greater when the project team adopts the agile methodology." This is because when an organization adopts an agile methodology, according to Horvath (2014) "this transition to agile, with all the uncertainty and organizational changes involved, 
inherently carries the possibility of triggering conflicts." Horvath (2014) further adds that teams have their own challenges when working in a group according to Tuckman's model as well as "the decentralization of management via self-organizing teams and of course the time pressure of working in short iterations" (Horvath, 2014).

According to Crawford et al. (2014), “agile software processes emphasize collaboration more than traditional methods. Collaborations and interactions are cited directly in two of the four values listed in the agile manifesto. Because of everything that involves communication contains the potential for conflict."

Possible reasons for conflicts in agile teams were highlighted by Ozawa and Zhang (2013): “complex interaction of values, attitudes, behavioral norms, beliefs, communication approaches by members of a project with vastly different values may give rise to misunderstanding and misinterpretation of intent that may result in conflict, mistrust, and underutilization of talents" (Ozawa and Zhang, 2013).

The influence of personality has been found to be a major reason for conflicts in agile teams as certain members might not be well suited to these teams because of their nature (Licorish, 2009; Hoda et al., 2010; Melo, 2013) Conflicting priorities have also been found to be one of the six decision obstacles identified in decision making by agile teams (Drury et al., 2012).

Barki and Hartwick (1994) showed that more collaboration provides more chances for conflicts. Their study showed that increased user participation is positively linked to increased conflicts and disagreements (Barki and Hartwick, 1994). Although conflict types and conflict management processes can have a wide range of impacts on the team or stakeholders' performance, these have not received much attention for research (Behfar et al., 2010).

According to Bano and Zowghi (2015), "the most prominent problems caused by user involvement are communication problems and misunderstandings between the users and the development teams leading to all kinds of conflicts." Conflicts always make their way between the team and users, therefore the management must adopt conflict management strategies to handle them effectively (Heiskari and Lehtola, 2009).

Melo (2013) found that problems are caused by not being "able to manage the conflicts regarding the work procedures, leading to turnover and decreased productivity in the short term (teams were unable to deliver for a while), as well as loss in both knowledge and team overhead after the turnover."

Moreover, conflict can reduce team productivity (Dreu and Weingart, 2003) because it "produces tension, antagonism, and distracts team members from performing their tasks” (Melo et al., 2013).

The importance of conflict management has also been shown by (Crawford et al., 2014), who argues that conflict "must be managed, not only as a way to optimize project success also to increase the satisfaction of project team members." In his view, software engineering lacks research about conflict management; therefore, he suggests investigating conflict management techniques and improving the software development process by designing a process which can manage conflicts.

This research paper aims to study the conflicts in agile software projects. Thus, we asked practitioners the following questions:

1. Can you please tell me about your background?

2. How many years of experience do you have working with agile software?

3. In your opinion, what are the sources of conflict in agile software projects?

4. If conflict occurs in a project, does it have any affect?

5. How does it affect project outcomes?

6. What kind of strategies are you using to handle these conflicts?

For the purpose of this study, no distinction has been made regarding types of conflict. Instead, we will use the term conflict incorporating all types of conflicts. Grounded theory refers to research methodology while Grounded theory refers to theory generated applying Grounded theory.

We conducted a qualitative study and Grounded theory study was used to analyze the data. The rest of the paper is organized as follows: Section 2 presents the methodology; Section 3 presents the results of the study and interview results are presented using the Glaser's Six C's coding model (context, condition, causes, consequences, contingencies, and covariance); Section 4 presents discussion and relevant literature; and finally the paper is concluded along with implications for future research.

\section{Methodology}

The reason we preferred to choose Grounded theory for our research is because this theory helps to analyze and understand the "phenomenon undergoing in the current scenario" (Glaser, 1992). Grounded theory tries to find and explain the answers to the following questions: "what's going on?", "what is the main problem of the participants?", and "how are they trying to solve it?" (Glaser and Strauss, 1967).

The reasons for using Grounded theory for our research are outlined as follows:

1. Grounded theory is said to be very well suited for research studies that involve social interactions between individuals and human behavior (Glaser, 1992). Since this study aims to study conflicts in agile software projects and conflicts always arise between individuals, this process has a lot of emphasis on social interactions and human behavior.

2. Another reason for using Grounded theory is that this methodology is a suitable research method for areas that are under explored (Birks and Mills, 2011). Research on conflict and conflict management has not received much attention for research in agile (Behfar et al., 2010) (Crawford et al., 2014) and consequently we think that more studies need to be conducted to explore the issue in this area.

3. Grounded theory is a powerful tool to gain insight into an individual's experiences, perceptions and their feelings about a particular research area. The main 
focus in Grounded theory is on the everyday life experiences, opinions and perspectives of participants; therefore, it is descriptive in nature and relies on people's words and opinions (Marshall and Rossman, 2014). Since our research is based on the experiences, opinions and perceptions of project managers to understand conflicts, their causes and strategies for handling them, Grounded theory is most suitable choice for our research.

\subsection{Data collection}

We performed 24 interviews with agile practitioners working in Norwegian software organizations. These organizations include companies which perform in-house development or consulting organizations who deliver projects to customers. The practitioners we interviewed had many years of experience within the software industry and working with agile methods and are project managers. We conducted semi-structured interviews through various media, including face to face (mostly) and Skype. Twenty four interviewees were selected based on the following criteria: (1) role (project manager); (2) number of years of experience in software project management; and (3) work experience and knowledge related to agile development. We asked practitioners open-ended questions. The sampling technique we used for our study is called nonprobability sampling (Devers et al., 2000).

Keeping the suitability for the research in mind, we used purposive sampling. Deliberate contact was made with the practitioners who had relevant experience with agile projects. We performed an internet search for the practitioners and after determining their suitability for our research question, we asked them to participate in the study. After agreeing upon a time and place, interviews lasted for 30-60 minutes.

We assured practitioners of anonymity regarding their names and organizations and therefore we will refer to practitioners with AP1-AP24. Practitioners' profiles are presented in Table 1.

\subsection{Data analysis}

In Grounded theory no guidance should be given to the interviewees to ensure they can talk about important points in the given context (Gorra, 2007). In our scenario the research context was conflicts. After asking about their background and experience, we asked the practitioners to tell us about conflicts. We let them speak about the topic before we asked them other relevant questions, for example "What strategies are you using to handle conflicts?" Important points arising from interviewee descriptions about the research area can be used by the researcher to generate codes, and categories are generated after grouping several relevant codes together (Gorra, 2007).

In Grounded theory data analysis is called coding. Coding using a systematic data analysis approach helps in understanding the interviewees' experiences and their interpretations of the world (Corbin and Strauss, 1990). Data analysis in Grounded theory is a continuous process that starts very early after conducting the first interview and continues until saturation is reached (Corbin and
Strauss, 1990). Fig. 1, Fig. 2, and Fig. 3 present levels of abstraction in Grounded theory.

\subsubsection{Open coding}

The first step of data analysis in Grounded theory is called open coding (Glaser, 1978, 1998). Open coding can be done on a word by word or line by line basis and line by line coding has been utilized here. Open coding is done by answering the following questions: "What is actually happening in the data?", "What is the main concern being faced by the participants?" and "What accounts for the continual resolving of this concern?” (Glaser, 1998, p. 140). Open coding helps to identify key concepts in the data, and then a suitable code that presents the key point is assigned to these key points (Georgieva and Allan, 2008). Table 2 presents examples of codes that were assigned to statements in the open coding process.

\subsubsection{Constant comparison}

After reading and coding of all interview transcripts, initial codes and categories emerge. Each of these emerging codes are compared to codes within the same interview transcript and with codes emerged in other transcripts to produce a higher level of abstraction called concepts. This procedure is repeated on the resultant concepts to produce a further higher level of abstraction called categories. This process is called the constant comparison method (Glaser and Strauss, 1967).

\subsubsection{Core category}

Open coding ends when the core category is selected (Glaser, 1992, p. 39). Here, the core category selected for this study was "conflicts". The core category should be central and should relate to several other categories (Glaser, 1978). There could be more than one potential core categories but a single one must be chosen. Glaser (2001, p. 201) states that the selection process requires careful consideration and commitment from the researcher and if more than one core category emerges within the study then the researcher can work on each of the core categories in separate research studies.

\subsubsection{Axial coding}

According to Strauss (1987), axial coding consists of "intense analysis done around one category [i. e., variable] at a time, in terms of paradigm items (conditions, consequences, and so forth)’” (p. 32).

"Axial coding involves re-building the data (fractured through open coding) in new ways by establishing relationships between categories and their subcategories" (Lawrence and Tar, 2013); categories that are developed through open coding are interlinked by establishing relationships between them in axial coding (Glaser, 1978).

These categories can be seen as pieces of a puzzle that are arranged together in the proper format. Every puzzle piece (category) is examined carefully to ascertain its relevance and accurate position. During the initial stages this procedure could be seen as trial and error, but with the passage of time theoretically sensitivity helps the researcher to make correct decisions more quickly and accurately. 
Table 1. Practitioners' profile

\begin{tabular}{cccc}
\hline Practitioners & Designation & Agile Methods worked with & Experience with agile \\
\hline AP1 & Project manager & Scrum, KANBAN & 10 \\
AP2 & Project manager & Scrum, KANBAN & 9 \\
AP3 & Project manager & XP, Scrum & 9 \\
AP4 & Project manager & XP, Scrum, KANBAN & 10 \\
AP5 & Project manager & Scrum, KANBAN & 8 \\
AP6 & Project manager & Scrum, KANBAN & 8 \\
AP7 & Project manager & XP, Scrum & 10 \\
AP8 & Project manager & Scrum, KANBAN & 10 \\
AP9 & Project manager & Scrum & 9 \\
AP10 & Project manager & Scrum & 8 \\
AP11 & Project manager & Scrum & 8 \\
AP12 & Project manager & XP, Scrum & 10 \\
AP13 & Project manager & Scrum, KANBAN & 10 \\
AP14 & Project manager & Scrum, KANBAN & 9 \\
AP15 & Project manager & XP, Scrum & 10 \\
AP16 & Project manager & XP, Scrum, KANBAN & 12 \\
AP17 & Project manager & Scrum, KANBAN & 8 \\
AP18 & Project manager & Scrum & 7 \\
AP19 & Project manager & Scrum, KANBAN & 9 \\
AP20 & Project manager & XP, Scrum & 8 \\
AP21 & Project manager & Scrum, KANBAN & 9 \\
AP22 & Project manager & XP, Scrum & 8 \\
AP23 & Project manager & XP, Scrum & 9 \\
AP24 & Project manager & XP, Scrum, KANBAN & \\
\hline & & & 9 \\
\hline
\end{tabular}

Table 2. Example of codes developed after open coding

Interview transcripts
I meet often conflict of interest with my back office

I need people with right competencies, right experience, right social skills

and back office want to sell out people available.

These people are not necessarily right for my project

For instance, I am very good at organizing teams creating good working environment but not analyzing and processing data.

I am not very analytic. I have a member in my team to look into these matters

I focus on project management.

I know little about product that other person make sure that product quality is good

\section{Codes}

Conflict of interest

Need right people for team

People allotted on availability basis

Not getting right people for team

Good organizer

Good at creating working atmosphere

Not good in analysing

Making someone else responsible for some tasks

Good at project management

Making someone else responsible for quality Wastage of time and energy

People will spend time and energy on things other than work 


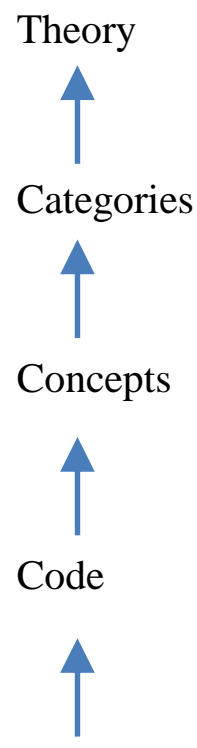

Key points in interview data

Fig. 1. Levels of abstraction in Grounded theory

Product owner is not form customer side

Too busy Product owner

Product owner is not a decision maker

The role of the product owner

Product owner don’t require technology understanding

Product owner requires functionality understanding

Demand some functionality that is not possible

Fig. 2. Underlying codes that gave rise to concept (the role of the product owner)

The role of the product owner

An inexperienced project manager

The customer s lack of knowledge about methodology

Organizational hierarchy in public companies

Contracting

Causes of conflicts

Scope aspect

Personal egos

Financial issues

Not getting the right team

Fig. 3. Underlying concepts that gave rise of category (causes of conflicts) 


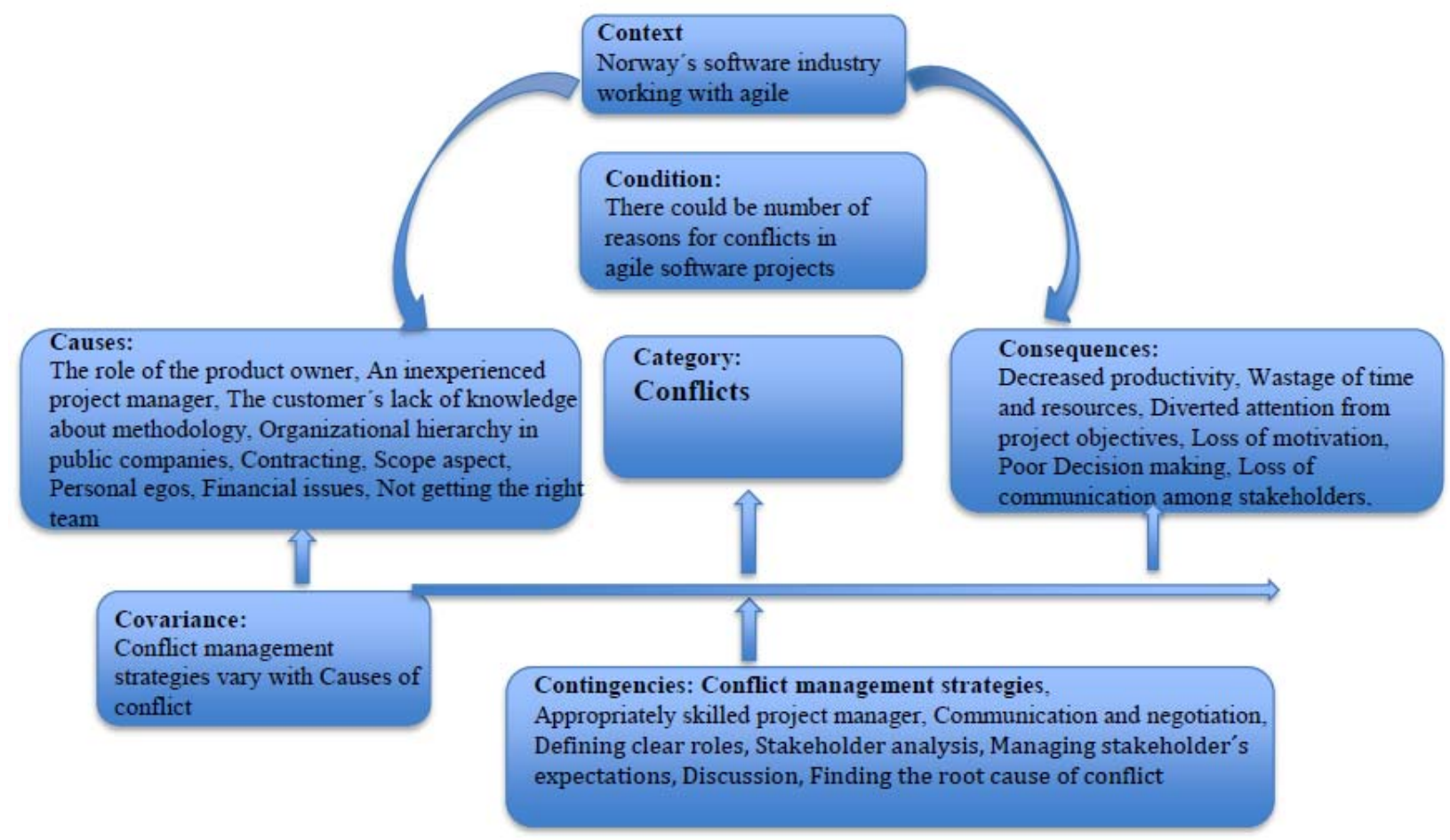

Fig. 4. The theory of conflict management depicted using the Six C's model (Context, Condition, Causes, Consequences, Contingencies, and Covariance) (Glaser, 1978)

\subsubsection{Selective coding}

After categories emerge and the core category is identified, the researcher can do selective coding. This means those categories that have a link with core category are considered. Therefore, selective coding helps to integrate and refine categories to form a theory which presents the phenomenon being investigated along with presentation of interlinks between concepts and categories (Darke et al, 1998).

Researchers use concepts and relational statements to explain "what is going on" (Strauss and Corbin, 1998). We have used Glaser's six Cs coding family (causes, contexts, contingencies, consequences, conditions), which is one of the various coding families used to represent the relationship between categories and ultimately generated theory (Glaser, 1978). In this research selective coding has been conducted around our core category "conflicts."

\subsubsection{Theoretical saturation}

Data collection and analysis in Grounded theory is done until theoretical saturation is reached (Glaser 1978, p. 71). This means data collection should stop when there is no new data emerging regarding categories or the relationships between them (Strauss and Corbin, 1998). For this study, we stopped data collection when we felt that no new categories were emerging.

\subsubsection{Memos}

Memos represent the theoretical connection between categories. These are ideas that the researcher writes down to gain a better insight into the determined categories.
Memo writing is an important part of Grounded theory research as these memos are helpful during the theory writing process (Glaser, 1978).

\section{Results}

In this section, we will present our theory. To present our results, we used Glaser's six Cs coding family (1978). This coding family (causes, contexts, contingencies, consequences, conditions) is one of the various coding families used to represent the relationship between categories and ultimately generate a theory (Glaser, 1978) and has helped us to illustrate our theory of conflict management (Fig. 4). We have used the six Cs model to present our results because there are certain causes of conflicts that have certain consequences. Thus, to present our findings in a concrete manner, the six Cs model was the most suitable choice.

In this model (Fig. 4), the core category "conflicts" lies at the center of the diagram. The relationship of each of the six Cs to the category is also represented in the diagram.

Selected quotations from the interview transcripts are presented in the following sections to provide a better insight along with necessary explanation of the concepts that gave rise to the categories. We interviewed 24 practitioners, but due to the space limitation we cannot discuss all the underlying points, concepts, or codes arising from the interviews that laid the foundation for the codes and categories.

\subsection{Context}


We conducted interviews with agile practitioners from different software development organizations in Norway. A detailed description is presented in Section 2.

\subsection{Condition}

As discussed in Section 1 that agile methods put emphasis on communication, collaboration and close customer involvement throughout the development of the project and therefore there is a higher likelihood of conflicts in agile software projects.

\subsection{Causes}

Grounded theory analysis of the data highlights the main causes of conflicts in agile software projects and these are outlined as follows: the role of the product owner, an inexperienced project manager, the customer's lack of knowledge about methodology organizational hierarchy in public companies, contracting, personal egos, financial issues, not getting the right team. Table 3 presents summary of all categories.

\subsubsection{The role of the product Owner}

One conflict that often arises between project managers and product owners is that the product owner wants to develop a functionality that is not possible (due to scope, budget or technological restrictions). According to practitioners, this is often because technologically developing that particular functionality is not possible. Other reasons may be that due to other constraints the project manager can't deliver what product owner is asking for.

"When a product owner wants something and it can't be done."__AP3

Practitioners believe that the product owner's role is particularly important. They believe that the product owner should have a role of a decision maker in the parent organization. He does not need to have knowledge of technology but he should have an understanding of the functionality.

"I think it's important to have a product owner that is involved and is a decision maker. Product owners don't need to have technology understanding but they need to have functionality understanding.”__AP14

According to practitioners the product owners sometimes lack a wide range of knowledge, but it is desirable if they have an understanding of functionality.

While working in one of the projects, AP14 encountered a product owner who was a professional person (IT person). Therefore, the project manager experienced the problem that the product owner was not available when needed and that person was not the decision maker; consequently, the project manager had to wait for a long time to get approval from the authorities.

"The professional product owner in this project was probably one of the big downfalls. She was not available (due to other work related commitments) and she was not a decision maker.”_AP6

Practitioners asserted that ideally the product owner is the person who is responsible for all communication and decision making, but in real life this level of maturity is not present.

"Project organization is in the hands of the product owner and the product owner is responsible for all communication and everything, which is a very ideal picture, and based on that some conflicts will arise because it's difficult to reach that level of maturity in this situation.”_AP10

Table 3. Categories generated for this research (along with numbers, presenting number of practitioners mentioned the specified category)

\begin{tabular}{|c|c|c|}
\hline \multicolumn{3}{|l|}{ Causes } \\
\hline The role of the product owner (14) & $\begin{array}{l}\text { An inexperienced project manager } \\
(12)\end{array}$ & $\begin{array}{c}\text { The customer's lack of knowledge } \\
\text { about methodology (10) }\end{array}$ \\
\hline $\begin{array}{c}\text { Organizational hierarchy in public } \\
\text { companies (7) }\end{array}$ & Contracting (6) & Scope aspect (6) \\
\hline Personal egos (5) & Financial issues (5) & Not getting the right team (4) \\
\hline \multicolumn{3}{|l|}{ Consequences } \\
\hline Decreased productivity (18) & Wastage of time and resources (13) & $\begin{array}{l}\text { Diverted attention from project } \\
\text { objectives (12) }\end{array}$ \\
\hline Loss of motivation (10) & Poor decision making (8) & $\begin{array}{l}\text { Loss of communication among } \\
\text { stakeholders (3) }\end{array}$ \\
\hline \multicolumn{3}{|l|}{ Conflict management strategies } \\
\hline $\begin{array}{l}\text { Appropriately skilled project } \\
\text { manager (20) }\end{array}$ & Communication and negotiation(15) & Defining clear roles (13) \\
\hline Stakeholder Analysis (9) & $\begin{array}{c}\text { Managing stakeholder's expectations } \\
\text { (9) }\end{array}$ & Discussion (7) \\
\hline Finding the root cause of conflict (2) & & \\
\hline
\end{tabular}

\subsubsection{An inexperienced project manager}


The respondents believe that sometimes conflicts arise due to the incompetencies of the project manager. For example, if the project manager is not competent enough and they are not equipped with the right skills needed to manage a project and people there are likely to be problems.

"Conflicts arise in two places. If the project manager doesn't know about a scrum there are more chances of conflicts, and this is also the case if the project manager doesn't conduct stakeholder analysis correctly as he doesn't involve the product owner. So, it is very important that the project manager and product owner are able to cooperate closely when doing stakeholder analysis.”_AP3

Another project manager we interviewed told us that he was the project manager on a big EU project and that the project in question might have been stopped a few months ago. The project was running at multiple locations and persons responsible at these locations did not convey the actual status of the project, resulting in delays and eventually the project being shut down. However, the bad part was that this project might have stopped quite early. Based on her experience we think that this project manager should have had a clearer grasp over the project status and deliverables in order to avoid such extreme situations.

\subsubsection{The customer's lack of knowledge about methodology}

According to practitioners customers tell the supplier company that the project should be done using agile methodologies. However, challenges arise here because an agile way of working puts a lot of responsibility on the customer's side and sometimes customers are not mature enough and lack knowledge about the way agile methods work.

"One of the main problems is that the customer demands that we work in agile. They ask for a methodology they don't have knowledge about. The challenge with agile is that it puts a lot of responsibility on the customer's side.”_AP13

Another problem highlighted by practitioners is that although customers come for meetings, they don't come as often as expected or required. Thus, in order to run work smoothly, project managers have to write things down and send them via email or wait for the meetings before they proceed further in the project. Every change request is handled in a formal way and project managers don't proceed further until they receive a reply approving the change request. As a result, everything is handled in a very formal way. This is necessary to avoid any kind of issues related to budgeting. According to the project managers interviewed here, this is an issue because in agile projects it is necessary to be quick in responding to changes but a lot of time and effort is put into making any changes. They believe it is necessary because if the customers do not formally approve any change requests then they will not pay for the extra costs incurred on the project. Project managers believe that if you are working in an agile way there needs to be a lot of trust between both parties and individuals need to be quick to respond to changes, but in reality this doesn't happen.

AP13 expressed his opinion about extra work as follows:
"It's formal, it's heavy, it is negative and they wonder what happens to lean/agile philosophy."

According to one respondent an extreme issue in one project he worked on last year was the customer's inability to define clear requirements.

"The customer always wanted to know how much it costs and the functional scope and prioritizing features and customers inability to clear requirement.”_AP20

Having continuous communication is necessary for successful delivery of the project. Sometimes, the problem arises when the project manager doesn't have direct communication with the actual stakeholders.

"We usually talk with workers who are not real stakeholders.”_ AP5

Practitioners asserted that due to lack of direct communication channels message often fail to reach the concerned managers. Another problem is that practitioners are facing is that customers are not present when they need them.

Practitioners asserted that the cause of conflict is that the customer is not mature enough to work in an agile way and as a result product owners can't understand the customer side. In these situations one of the people from the supplier company acts as the product owner. In this case, there are further chances of conflicts because customers are not being represented or do not have any say about the project as often as they need to.

"I have been working with smaller projects in a context where the customer is not very mature and not a mature buyer of software service and when you do that it's very difficult to tell one customer representative you must be the product owner.”_AP10

\subsubsection{Organizational hierarchy in public companies}

Public organizations' way of working doesn't support agile philosophy because a lot of bureaucracy is involved in these organizations.

"Huge companies have a lot of politics and bureaucracy.”_AP11

"Public organizations work in a more waterfall way than in agile.”__AP9

Respondent believe that bureaucracy on the customer's side means that they will have more control over the project. Another source of conflict is that when agile and waterfall processes are put together to work, conflicts often arise due to different mindsets and approaches.

"The trouble came when I realized that I have to combine waterfall and agile. I realized that they (customers) need control (over the project).”_AP19

Practitioners believe that this way of working cannot be changed in a quick manner.

"This way can't be changed at once because these are huge organizations.”_AP13

Practitioners believe that the role of the product owner is extremely challenging in these organizations. The reason is that the product owner is not the actual decision maker. For all changes, project managers have to talk to someone else on the customer side to get the necessary approvals. One of the project managers experienced a 
three week delay in a project due to these formal procedures. Contracts state that if the delay is caused by the customer's company they will be charged for this. Respondents argue that no one wants the situation of sitting idle and doing nothing. According to practitioners, private companies have different procedures and product owners understand that if they are the product owner they are supposed to take decisions.

"It's different in private companies as product owners understand that if I am the product owner I am supposed to take decisions. This is one of the cultural things.”_AP16

Another challenge with public companies is that they want to get every aspect specified in advance. Practitioners experienced that when they worked with small private companies they found that they are more adapted to working in an agile way. Practitioners believe that this has a lot to do with maturity and culture. In the traditional method of working, planning is done ahead but the plan is not always accomplished; on the other hand, in agile methods the opposite is true as to the focus is on delivering value and not caring much about detailing everything in advance. This means there is also a clash of cultures. The practitioners argued that bureaucracy in the public sector is really not very good at doing things in a quick manner as required in agile work.

\subsubsection{Contracting}

Practitioners believe that a major area that causes conflict is related to contracting because companies are using agile with fixed price contracts. According to the responses collected here, public companies have more waterfall approaches than agile ones and consequently they wanted to use fixed price contracts in agile projects. Practitioners asserted that using agile with fixed price contracts is a significant challenge in agile projects.

"You use a contract with fixed price and it's not possible to use agile with fixed price.”_AP5

"The contract is difficult and it is even more difficult that they demand and want us to be agile knowing that they are not agile themselves.”__AP13

"We have conflicts because we have more fixed price contracts." AP17

The reason for this is that when a fixed price contract is used the project requires a detailed specification that is planned ahead just like in a waterfall process.

"Contracting is probably a big source of conflict arising, especially in public companies.”__AP20

\subsubsection{Scope aspect}

Practitioners asserted that one cause of conflict is that product owners want to have more functionality added without the necessary changes in other aspects.

“They (product owners and customers) want more features and I have deadlines to reach expectations.”_AP4

One of the project managers experienced a failure in a big project which was about to be terminated several days later. When we discussed the reason for this failure, he asserted that:
"Customer expected more than we promised to deliver and actually the customer chose a product that we could not deliver."_AP14

According to practitioners the biggest reason for conflict in their projects was the fact that the customers provided high level specifications and expected get everything they asked for. When they use this scope to define sprints and details, serious issues arose because the customers did not define appropriate specifications or scope at the sprint level.

"I think they want it all in a bag."__AP14

"In our situation, conflicts are obviously that the customer has a waterfall perspective and as a result I think the biggest problem is the scope aspect.”__AP22

\subsubsection{Personal egos}

Practitioners believe that although conflicts may arise due to different causes, personal egos can also generate conflicts. This comes under the category of relationship conflicts. One respondent's view is as follows:

"I suppose that roles and responsibilities conflicts come from many resources. One aspect is psychology and that is because of personal egos. People tend to form groups or strong small sub teams where they all have one or two technological strengths.”__AP11

\subsubsection{Financial issues}

The interview data suggested that another cause of conflicts is budget related issues. These often arise due to change requests from the customer's side, which creates discussion regarding whether this is based on the original requirements base or if there is a new requirement. Practitioners told us that then there is always a financial discussion relating to who should bear the costs.

"I see many conflicts we have are based on finance.... Then there is financial discussion about who should bear these costs; we argue that the customer should take them and they argue we should take them.”_AP7

"You have too much conflict where the main decision maker is the person who places the emphasis on money.”_AP14

\subsubsection{Not getting the right team}

Practitioners revealed that one area of conflict is that project managers want to have a team of competent, skilled, experienced and social competent individuals in order to deliver best results. Conflict of interest arises when back office allocates people to that project based purely on availability. Practitioners asserted that this is often the case in consulting businesses and in one practitioner's view the available people might not be the right people for the project.

"I often meet conflict of interest with my back office because I need new people in a project. I want people with the right competencies, the right experience, the right social skills and the back office wants to send out the people available. These people are not necessarily right for my project.”_AP1

"What I see problem with management is that when I need certain people in my team due to their capabilities and fit in the team but I don't get them.”_AP16 


\subsection{Consequences}

The consequences of these conflicts could range from minor to major. People involved in the conflict can divert their attention from the primary objectives by becoming involved in unnecessary activities. Conflicts if not addressed properly can have many consequences including the following:

\subsubsection{Decreased productivity}

Practitioners think that if individuals are more often involved in conflicts, they could have decreased productivity.

"I think if you are busy with other things then how can you deliver something that you are supposed to deliver?”__AP11

"Whenever there is such issue it leads to poor working environment with less focus on work.”_AP14

\subsubsection{Wastage of time and resources}

Practitioners believe that a lot of time, effort and resources might be needed to resolve conflicts. If these conflicts are minor they can be solved quickly, otherwise a significant amount of time, effort and resources is required to create a harmonious solution that is acceptable for all parties.

"I see a lot of time is wasted in making people agree on one solution."__AP21

"A lot of time is wasted in handling such issues. Not bring benefit to anyone.”__AP2

\subsubsection{Diverted attention from project objectives}

Practitioners believe that one of the consequences is that individuals involved in conflicts might lose sight of the project objectives.

"People might spend time on unnecessary
tasks.”_AP17

"People can find other motives and they might not concentrate on tasks assigned to them.”_AP7

\subsubsection{Loss of motivation}

Respondents believe that unattended conflicts can cause major disruptions in work and processes. Individuals involved can lose work related motivation thus halting progress of the project work.

"People might not work the way they are supposed to.”_AP2

"One thing which I see is that one might loss motivation to do something.”__AP8

\subsubsection{Poor decision making}

Practitioners asserted their opinion that conflicts can result in poor decision making regarding work related activities because a significant amount of energy, time and resources will be wasted on conflicts. When the team has conflicting priorities they tend not to perform well. Agile methods heavily emphasize self-organizing teams with considerable autonomy related to tasks and decision making, and practitioners think that conflicts can hamper the self-organizing behavior of these teams.

"If conflicts are not solved I think then people could not reach goals together because of lack of shared understanding about goals.”__AP11
"If things are not working as they should these might affect people in multiple ways. For example they might find them stuck in things which are not really beneficial to do....Due to conflicts, it is not possible to catch or reach common goals because you don't have shared goals. It might also affect the way you make decisions to reach your goals.”__AP13

\subsubsection{Loss of communication among stakeholders}

Practitioners argue that if there are conflicts then this may lead to further decreased communication or loss of communication among stakeholders which may create further misunderstandings and ultimately becomes the reason for more conflicts. Loss of communication further affects the productivity of the members,

"People have egos, therefore they stop talking to people they have conflicts with.”__AP9

"The worst part is when you let things go on without actually getting the root causes to surface. People really don't feel comfortable to talk with people they have. As a result, conflicts may remain hidden.”__AP21

\subsection{Contingencies: Conflict management strategies}

We have discussed the causes and consequences of conflicts. We will now describe strategies that are being used or can be used by practitioners to avoid or resolve conflicts in agile software projects. These include appropriately skilled project manager, communication and negotiation, defining clear roles, stakeholder analysis, managing stakeholder's expectations, discussion, finding the root cause of conflict.

\subsubsection{Appropriately skilled project manager}

Practitioners believe that project managers need to be equipped with conflict management strategies and they should have an objective approach towards doing their job. When we asked practitioners about the skills these individuals should have to handle conflicts, they argued that education, experience, communication skills, being open to changes and a service minded attitude are highly influential skills for a project manager. They should be good at organizing teams and creating a good working environment as well as knowledge about project management skills. Finally, they must be open minded and should have interpersonal skills.

"Experience, learning to understand the organization and communication skills have a kind of service minded attitude.”_AP15

"I think you need to have a person with leadership skills able to go in and take direction.”__AP11

Practitioners argued that every project manager has different skills, competencies and personalities. Regardless of which skills they possess they should make sure to have someone else in the team to take care of areas where they are less experienced:

"For instance, I am very good at organizing teams and creating good working environment but not analyzing and processing data. I am not very analytical. I have a member in my team to look into these matters, and I focus on project management. I know little about the products and other people make sure that product quality is good.”_AP1 
Practitioners stated that project managers should have a solid understanding of agile development. They also need to be able to manage the expectations of the customer.

Furthermore, practitioners believe that project managers should be enthusiastic and ready to embrace any changes along the way.

"The project manager should be enthusiastic, open to changes, and should not take things not personally.”__AP4

"It's good to be open-minded and have interpersonal skills to understand people and customers.”__AP21

\subsubsection{Communication and negotiation}

Communication and negotiation play a vital role in solving a conflict. Communication is especially emphasized in agile methods and therefore practitioners believe that conflicts should be resolved with communication and negotiation.

“Communication matters to keep everyone
happy.”_AP15

"The project manager should handle contracts and external communication to prevent conflicts.”_AP17

\subsubsection{Defining clear roles}

Another indication in the interviews is that a project manager needs to define clear roles otherwise there are more chances of conflicts regarding roles and responsibilities.

"Project managers need to define roles clearly because if they don't define roles clearly it is possible that at some point you might end with two project managers, i.e. it is possible that the product owner will start acting like a project manager. The project manager needs to be very clear about his own role.”__AP3

Making responsibility clear can help to ensure that conflicts related to this aspect may not appear.

\subsubsection{Stakeholder analysis}

The respondents argued that conflicts can be minimized if all the relevant stakeholders are involved and managed properly. They further suggested that stakeholder analysis must be done by the project manager to determine the key stakeholders.

"I think the real way it (conflict) can be minimized is doing stakeholder analysis of where your stakeholders are coming from and ensuring that you are meeting their requirements. You can see who the key stakeholders are and then you can involve them more.... You can see other stakeholders that should be kept informed etc.”_ AP19

"If you (project manager) communicate enough with stakeholders you should be good at collaboration.”__AP19

"More work should be done to involve all people.”_AP15

\subsubsection{Managing stakeholders' expectations}

Practitioners asserted that in order to avoid conflicts, the project manager should be able to handle customer expectations whilst also maintaining a smooth flow of communication among all stakeholders involved in a project.
"It is important to be able to control customer expectations. Project managers have to have a deep knowledge and good communication with the scrum master and developer.”__AP17

"When you are working as an external project manager then you have to do a lot of customer expectation management.”_AP17

"Understanding customer expectations.”

AP20

\subsubsection{Discussion}

The interview data suggests that a project manager can solve problems by discussing them with people. Discussing a problem or conflict can help to find the root cause of the conflict along with its solution. Practitioners believe that conflicts should be discussed openly to find the appropriate solution for it as if these issues are left unresolved they can become more problematic. After reaching a solution everyone must agree to the solution. One practitioner adds:

“I fix it by discussing it with people.”_AP4

"The best solution is to sit with them and talk about the issues. Only discussion can lead to some useful result.”_AP3

\subsubsection{Finding the root cause of conflict}

Chance of conflicts cannot be removed but the likelihood of such incidents occurring can be minimized. However, if conflicts have arisen, it is necessary to find out:

1. What are the root causes of the conflict?

2. What are necessary steps that should be taken to resolve the conflicts and create harmony among individuals?

From the interview data, it is evident that conflicts arose due to reasons that cannot be completely eliminated. Therefore, we suggest careful tackling of these issues. Respondents believe the primary reasons for conflicts should be investigated before taking any steps towards their resolution.

"First thing to know is what is the reason? It is important if you want to get a solution.”__AP4

"Without knowing what is the reason behind, you can not find a solution." AP13

\subsection{Covariance}

Covariance refers to how a change in one category can have an effect on other categories (this relationship is shown by arrow pointing towards left). From the interview findings, we found that the categories related to causes of conflict are influenced by conflict management strategies. For example, categories related to causes of conflicts (the role of the product owner, an inexperienced project manager, the customer's lack of knowledge about methodology organizational hierarchy in public companies, contracting, personal egos, financial issues, not getting the right team) and the categories related to conflict management strategies (appropriately skilled project manager, communication and negotiation, defining clear roles, stakeholder analysis, managing stakeholder's expectations, discussion, finding the root cause of conflict) have an effect on each other and vary accordingly.

\section{Discussion}


A number of stakeholders are involved in a project. Different stakeholders have "different motivations and interests" (Krane et al., 2012), and these are major sources of conflicts in a project. One major stakeholder is the team. Agile methodologies put more emphasis on selforganizing teams (Hoda et al., 2013; Oza et al., 2013; Hoda and Murugesan, 2016). In agile projects, teams are not changed as often as in waterfall projects (Adkins, 2010). Therefore, if conflicts remain unresolved in waterfall projects it is not a big issue but in agile projects if teams remain the same throughout the project conflicts cannot be left untreated. As a result, in agile projects, it is vital to first determine the severity of conflict before attaining a solution (Adkins, 2010). A team can be guided through this phase in finding a solution to the problem. Respondents' opinions about stakeholder analysis are in accordance with this literature.

The effect of communication was shown by Kawalek and Wood-Harper (2002) in their paper. They described that user involvement can increase communication and therefore conflicts can be prevented. Suggestions from the study participants of involving all stakeholders in communication and negotiation are in accordance with the literature.

Practitioners asserted that project managers should be competent enough to handle conflicts if they arise. This is in accordance with Robey and Farrow (1982), who suggest that strategies for conflict resolution must be prepared in order to encounter any kinds of conflicts that arises during the project life cycle. Project managers should be able to detect the early signs of conflict and take the necessary steps to solve them effectively before they become huge or insurmountable. Practitioners' opinions about communication and collaboration are in accordance with Ahimbisibwe et al. (2015), who argue that team members should have internal project communication to increase information sharing which in turn increases the level of collaboration and cohesion. This results in less conflict among team members. Detecting early signs of conflicts is in accordance with Jun et al. (2011), who suggest making arrangements to resolve conflicts at the very early stages to ensure greater satisfaction from the customer. Practitioners believe that conflicts can result in project delays. This is in line with the research of Yetton et al. (2000) which shows that conflicts among team members can result in project delays and the budget being exceeded.

Practitioners suggested that in order to avoid conflicts, stakeholder analysis should be performed to involve all stakeholders in the project. This is in accordance with May (1998), who suggested that all stakeholders should be given an opportunity to share their point of view and without these remedies there are more chances of conflicts between the organization and customers and within the development team. The respondents' opinions about communication and collaboration are in accordance with Highsmith (2002), who argued that collaboration and good communication helps to reduce conflicts among stakeholders and prevent misunderstandings and thus increases knowledge sharing.

Since customers are investing money in the project they want to get the maximum value and benefit from it. Product owner is the person who is representative of the customer side therefore product owner has all the interests related to get the maximum benefit from the project. The project team is concerned with delivering the project according to time and budget (Krane et al., 2012); as shown by Turner and Müller (2004), these two interests and priorities lead to conflicts. Project managers should keep in mind this fact and design strategies accordingly.

Practitioners' opinions about having a balanced team is in accordance with Reel (1999), who stated that "having too many stars creates ego issues and distractions, while not having enough can leave the team struggling with small problems”.

People involved in the conflict can divert their attention from the primary objectives by becoming involved in unnecessary activities (Rubin et al., 2003). Individuals involved in these conflicts can get physical or psychological health problems (Rubin et al., 2003). Crawford et al. (2014) states that "persistent conflict complicates the management of the projects, causes practitioners to constantly disagree with each other about requirements, methods, techniques and solutions. The continued conflict damages the communication, coordination and control, reducing the team performance level and affecting the final quality of the product, the project deadline accomplishment and costing.” Therefore, conflicts should not be left unattended.

Conflicts can be minor and ignorable or major with severe impact. We have summarized five levels of conflicts in Table 4. These five levels of conflicts were described by Speed Leas (1998) and further elaborated by Adkins (2010) in her book on team's perspectives, but here they are written from the perspective of stakeholders involved in a project. We suggest that conflicts should be resolved before they reach level 4 or 5 or become insurmountable. Appropriate strategies to resolve conflicts must be followed because if these conflicts are not resolved they can "hinder communication and collaboration, resulting in decreased productivity of your teams, or even worse” (Horvath, 2014).

\section{Implications}

This theory of conflict management has implications for both theory and practice. These are discussed below.

\subsection{Implications for theory}

As discussed above, using an agile approach provides more chances of conflicts and consequently appropriate strategies must be taken into account to avoid or resolve conflicts. The implications of our conflict management theory are outlined as follows.

\subsubsection{Clarity regarding roles and responsibilities}

The major concerns of practitioners were that they were facing roles and responsibilities conflicts, which could be solved by establishing a responsibility matrix. This is presented as a strategy in our study (Siddique and Hussein, 2016) in order to prevent such conflicts. Making a clear distinction regarding who is responsible for what can help to avoid ambiguities between individuals, resulting in fewer conflicts. 
Table 4. Levels of conflicts adapted from Spree Leas (Oza et al., 2013)

Levels of , 124 £ubna, S. and Bassam, A. H.

Description

Conflicts at this stage are often due to difference of opinions and misunderstandings. These can also happen due to conflicting goals and values. At this stage collaboration

Level 1: Problem to Solve among stakeholders is present and stakeholders can work on the conflict if it is a result of miscommunication. An optimistic attitude is present at this level. Adkin (2010) regards level 1 conflicts as "constructive disagreement".

Level 2: Disagreement

At this level, stakeholders can distance themselves from each other; this results in disagreements and decreased initiatives to solve the problem.

Level 3: Contest

At this level multiple issues accumulate together resulting in a significant problem. Power politics can happen. The focus is more on the contest than on winning.

Level 4: Crusade

At this level people start thinking that other people will not change; therefore, they believe the only option is removing either themselves or the other person from the team.

Level 5: World war

People become so destructive towards each other that they think that no constructive solution is possible at this stage.

\subsubsection{Understanding and managing Stakeholders' expectations}

Stakeholder analysis must be performed by the project manager in order to involve every important stakeholder in the project. Important stakeholders' expectations should be managed properly and all viewpoints must be taken into account in order to avoid conflicts at later stages (May, 1998).

Keeping in view stakeholders' importance, Johnson et al. (2016) suggested that project managers should engage themselves effectively in stakeholder management right from the beginning.

\subsubsection{Communication, negotiation and discussion}

Instead of suppressing the conflicts, all kinds of conflicts should be surfaced and openly discussed with the concerned parties in order to reach a consensus. Otherwise, they can become insurmountable.

According to Hung and Lin (2013), a "high level of effective communication not only diminishes the negative impact of relationship conflict”, it also increases team satisfaction.

In terms of maximizing an agile team's effectiveness, effective coordination is suggested to be an important factor by Strode et al. (2012). They also presented a strategy for effective coordination.

\subsection{Implications for practice}

The conflict management theory presented in this paper has practical implications and this can be used by project managers for agile software projects, traditional software projects or any other types of projects in general.

\section{Evaluating grounded theory}

The Grounded theory study "does not intend to generate factual results or accurate descriptions, but presents an integrated set of plausible, theoretical hypotheses about an underlying pattern of behaviour" (Breckenridge, 2010, originally from Glaser and Strauss, 1967). According to Breckenridge (2010), "the emergent grounded theory offers an integrated probability statement that is not intended to be verified as right or wrong, but instead has relevant applicability and modifiability within the substantive area”. Therefore, grounded theory should have fit, work, relevance and modifiability (Glaser, 1978).

\subsection{Fit}

Fit refers to the validity of concepts and categories and their fit in the data. Glaser (1978) suggests that "the analyst's goal is to ground the fit of categories as close as he can” (p. 4).

To ensure fit, researcher should avoid a pre-literature review in order to pre-conceptualize concepts and categories so that data analysis is performed without preassumptions about the research topic. Following these guidelines, no literature review has been conducted before all concepts and categories emerged.

\subsection{Work}

Work describes the ability of the theory to "explain what happened, predict what might happen and interpret what is happening in an area of substantive or formal inquiry" (Glaser, 1978 p. 4). The participants' main concern must be well presented in the theory and in this study the main concern was conflict and conflict management. Data analysis and systematic generation of categories helps to generate concepts, codes and categories which accurately present what happened in the area of formal inquiry. The main concern for this study is conflict and conflict management with an accurate depiction (based on data) of what is happening in this area.

\subsection{Relevance}

Relevance refers to whether the theory is grounded in the data and systematically developed through analysis. Relevance can be ensured by applying Grounded theory procedures and problems and resolutions should emerge from the data.

Accordingly, all the causes for conflicts, consequences of conflicts and strategies for conflict management categories have emerged from the data.

\subsection{Modifiability}

Modifiability presents the ability of the presented theory to be altered through adding more relevant data (Thulesius et 
al., 2003). Grounded theory is "ever developing entity, not as a perfected product" (Glaser and Strauss, 1967, p. 43). After generating grounded theory, it should not be intended to be proven but rather further modified through constant comparison of categories emerging from further data collection (Glaser, 2003). The theory emerged "is only ever partially closed as new ideas will always hone it to better suit current circumstance” (Breckenridge, 2010). The theory of conflict management presented in this study is in a transitory state and is open to modification with new incidents, code and categories in the substantive area.

\subsection{Limitations}

This study has the following limitations:

1. Grounded theory research is strongly context specific; therefore, it cannot be generalized to a large population.

2. Furthermore, we collected the data not with specific project cases in mind but rather based on the collective experiences of the informants

3. All of the practitioners interviewed were project managers. This study only represents the viewpoints of project managers with the exclusion of all others.

4. Due to small sample, these findings might not be generalized to a larger population.

5. For the purpose of this study, no distinction has been made regarding types of conflict; instead, the term conflict is used to incorporate all types of conflict. This study is not particularly written about conflicts in agile teams. This study has taken into account conflicts from project managers' perspectives. Therefore, it depicts conflicts with the management, conflicts with product owner, conflicts with customers, conflicts with suppliers and conflicts within teams.

6. Conflict management theory presented in this study is not presented to participants for testing because Glaser (2001, p.11) recommends for not doing so. Doing so can provide wrong validity check. The reason is they are unaware of empirical details that gave rise to codes, concepts, categories and theory.

\section{Research contribution and future work}

This study has made a contribution to the existing body of knowledge about conflicts in general and conflicts in agile software projects in particular. Since there is a lack of conflict research in agile projects (Behfar et al., 2010; Crawford et al., 2014), this paper has endeavored to address this research gap. Although significant research has been conducted regarding teams and productivity, research focusing solely on conflicts issue is still missing.

Systematically generating categories from the data means all results are grounded (based) in the data. These are not hypotheses but instead are based on and driven by real world experiences of project managers working with agile projects. In future research, we intend to study in each of the categories (causes, consequences, strategies) of conflict presented above along with their effect on various stakeholders in more depth. One of the abilities of the grounded theory is it can be modifiable through more data collection and analysis (Thulesius et al., 2003). Future research may focus on causes of conflicts and their consequences to measure them quantitatively in order to find more empirical evidence. The limitations of this study already presented in terms of the specific context; we intend to do more work to make these findings generalizable to a wider population.

\section{Conclusion}

In this paper, we have discussed conflicts in agile software projects. The interview data suggested several possible sources of conflicts in agile software projects. These include the role of the product owner, an inexperienced project manager, the customer's lack of knowledge about methodology organizational hierarchy in public companies, contracting, personal egos, financial issues, not getting the right team. Based on their experiences, practitioners suggested various strategies to handle conflicts. Although there are several sources for conflicts, a lack of affective communication could be the main reason for unnecessary misunderstandings and conflicts being generated. In order to avoid conflicts, agile principles must be adhered to. The principles of communication and collaboration help to foster positive relationships among stakeholders. It is very important that these conflicts are managed in a manner that can support collaboration and cooperation among all stakeholders. Strategies for handling conflicts include: appropriately skilled project manager, communication and negotiation, defining clear roles, stakeholder analysis, managing stakeholder's expectations, discussion, finding the root cause of conflict. The project manager should have education, experience, communication skills, be open to changes and have a service minded attitude. This individual should also be good at organizing teams and creating good working environment. He should have knowledge about project management skills and he must be open minded and should have interpersonal skills. The project manager should have the right skills to avoid conflicts and if these occur he needs to be capable of handling them. Defining clear roles and managing customer expectations are important as this can prevent confusion, which can in turn create conflicts. If conflicts occur, the project manager should discuss the issues with the concerned stakeholders to obtain a suitable solution; thus, the project manager needs to be competent enough to handle such issues affectively.

\section{References}

Adkins, L. (2010, July). Coaching agile teams. AddisonWesley Signature Series (Cohn). [Online]. Available: https://dzone.com/articles/agile-managing-conflict.

Bano, M. and Zowghi, D. (2015). A systematic review on the relationship between user involvement and system success. Information and Software Technology, 58, 148-169.

Barki, H. and Hartwick, J. (1994). User participation, conflict, and conflict resolution: the mediating roles of influence. Information Systems Research, 5(4), 422438.

Birks, M. and Mills, J. (2011). Grounded theory: A practical guide. London: Sage Publications.

Behfar, K. J., Mannix, E. A., Peterson, R. S., and Trochim, W. M. (2010). Conflict in small groups: The meaning and consequences of process conflict. Small Group Research, 1046496410389194.

Bradford, K. D. and Weitz, B. A. (2009). Salespersons' management of conflict in buyer-seller relationships. 
Journal of Personal Selling \& Sales Management, 29(1), 25-42.

Breckenridge, J. (2010). Being person driven in a service driven organisation: a grounded theory of revisioning service ideals and client realities (Doctoral dissertation, Queen Margaret University).

Corbin, J. M. and Strauss, A. (1990). Grounded theory research: Procedures, canons, and evaluative criteria. Qualitative sociology, 13(1), 3-21.

Cohen, D., Lindvall, M., and Costa, P. (2004). An introduction to agile methods. Advances in Computers, 62, 1-66.

Crawford, B., Soto, R., de la Barra, C. L., Crawford, K., and Olguín, E. (2014, June). Agile software teams can use conflict to create better products. International Conference on Human-Computer Interaction. Springer International Publishing, pp. 24-29.

Darke, P., Shanks, G., and Broadbent, M., (1998). Successfully completing case study Research: Combining rigour, relevance and pragmatism. Info Systems Journal, 8, 273-289.

Devers, K. J. and Frankel, R. M. (2000). Study design in qualitative research--2: Sampling and data collection strategies. Education for health, 13(2), 263.

de Wit, F. R., Greer, L. L., and Jehn, K. A. (2012). The paradox of intragroup conflict: a meta-analysis. Journal of Applied Psychology, 97(2), 360.

Dreu, C. K.W. D., and Weingart, L. R. (2003). Task versus relationship conflict, team performance, and team member satisfaction: a meta-analysis. Journal of Applied Psychology, 88(4), 741-749.

Drury, M., Conboy, K., and Power, K. (2012). Obstacles to decision making in agile software development teams. Journal of Systems and Software, 85(6), 12391254.

Georgieva, S. and Allan, G. (2008). Best Practices in Project Management through a Grounded Theory Lens, Electronic Journal of Business Research Methods, 1, 43-52.

Glaser, B. G. (2003). The grounded Theory Perspective II: Description's Remodelling of Grounded Theory Methodology Mill Valley, California: Sociology Press.

Glaser, B. G. (1978). Theoretical Sensitivity: Advances in the Methodology of Grounded Theory. California: Sociology Press.

Glaser, B. G. (1992). Emergence vs Forcing: Basics of Grounded Theory Analysis. California: Sociology Press.

Glaser, B. G. and Strauss, A. L. (1967). The Discovery of Grounded Theory: Strategies for Qualitative Research. London: Wiedenfeld and Nicholson.

Glaser, B. (1998). Doing Grounded Theory: Issues and Discussions. California: Sociology Press.
Glaser, B.G. (2001). The Grounded Theory Perspective: Conceptualization Contrasted with Description: Sociology Press, CA, Mill Valley.

Gorra, A. (2007). An analysis of the relationship between individuals' perceptions of privacy and mobile phone location data-a grounded theory study. Doctoral dissertation, Leeds Metropolitan University.

Heiskari, J. and Lehtola, L. (2009, December). Investigating the state of user involvement in practice. In Software Engineering Conference, 2009. APSEC'09. Asia-Pacific. IEEE, pp. 433-440.

Horvath, K. (2014, October 8). How to Manage Conflict in an Agile Environment with PM Tools. [Online]. Available: http://intland.com/blog/projectmanagement-en/how-to-manage-conflict-in-an-agileenvironment-with-pm-tools/.

Hoda, R., Noble, J., and Marshall, S. (2010). Organizing self-organizing teams. Proceedings of the 32nd ACM/IEEE International Conference on Software Engineering - ICSE'10, vol. 1, ACM. New York, NY, USA, pp. 285-294.

Hoda, R. and Murugesan, L. K. (2016). Multi-level agile project management challenges: A self-organizing team perspective. Journal of Systems and Software, 117, 245-257.

Hoda, R., Noble, J., and Marshall, S. (2013). Selforganizing roles on agile software development teams. Software Engineering, IEEE Transactions on, 39(3), 422-444.

Highsmith, J. (2002) Agile Software Development Ecosystem. Boston: Addison Wesley.

Hung, K. P. and Lin, C. K. (2013). More communication is not always better? The interplay between effective communication and interpersonal conflict in influencing satisfaction. Industrial Marketing Management, 42(8), 1223-1232.

Jehn, K. A. (1995). A multi method examination of the benefits and detriments of intragroup conflict. Administrative Science Quarterly, 40(2), 256-282.

Jehn, K. A., and Bendersky, C. (2003). Intragroup conflict in organizations: A contingency perspective. Research in Organizational Behavior, 25, 189-244.

Johnson, N., Creasy, T., and Fan, Y. (2016). Recent trends in theory use and application within the project management discipline. Journal of Engineering, Project, and Production Management, 6(1), 25-52.

Jun, L., Qiuzhen, W., and Qingguo, M. (2011). The effects of project uncertainty and risk management on IS development project performance: A vendor perspective. International Journal of Project Management, 29(7), 923-933.

Kawalek, P. and Wastell, D. G. (2002). A Case Study of the Use of the Viable System Model in the Organization of Software Development. pp. 120-134.

Krane, H. P., Olsson, N. O., and Rolstadås, A. (2012). How project manager-project owner interaction can 
work within and influence project risk management. Project Management Journal, 43(2), 54-67.

Lawrence, J. and Tar, U (2013). The use of grounded theory technique as a practical tool for qualitative data collection and analysis. The Electronic Journal of Business Research Methods, 11(1), 29-40.

Leas, S. B. (1998). Discover Your Conflict management Style. Rowman \& Littlefield.

Licorish, S., Philpott, A., and MacDonell, S. G. (2009). Supporting agile team composition: a prototype tool for identifying personality (in) compatibilities. Proceedings of the 2009 ICSE Workshop on Cooperative and Human Aspects on Software Engineering. CHASE '09: IEEE Computer Society. Washington, DC, USA, pp. 66-73.

Marshall, C. and Rossman, G. B. (2014). Designing Qualitative Research. London: Sage Publications.

May, L. J. (1998). Major causes of software project failures. CrossTalk: The Journal of Defense Software Engineering, 11(6), 9-12.

Melo, C. D. O., Cruzes, D. S., Kon, F., and Conradi, R. (2013). Interpretative case studies on agile team productivity and management. Information and Software Technology, 55(2), 412-427.

Oza, V., Kettunen, P., Abrahamsson, P., and Münch, J. (2013). Attaining high-performing software teams with agile and lean practices: An empirical case study. arXiv preprint arXiv:1311.6933.

Ozawa, H. and Zhang, L. (2013, August). Adapting agile methodology to overcome social differences in project members. Agile Conference (AGILE) IEEE, pp. 82-87.

Reel, J. S. (1999). Critical success factors in software projects. Software, IEEE, 16(3), 18-23.

Reid, D. A., Pullins, E. B., Plank, R. E., and Buehrer, R. E. (2004). Measuring buyers' perception of conflict in business-to-business sales interactions. The Journal of Business and Industrial Marketing, 19(4), 236-249.

Robey, D. and Farrow, D. (1982). User involvement in information system development: A conflict model and empirical test. Management Science, 28(1), 73-85.

Rubin, J. Z., Pruitt, D. G., and Kim, S. H. (1994). Social Conflict: Escalation, Stalemate, and Settlement. New York: Mcgraw-Hill Book Company.

Siddique, L., and Hussein, B. A. (2016). Grounded theory study of the contracting process in agile projects in Norway's software industry. Journal of Modern Project Management, 4(1), 52-63.

Strauss, A., and Corbin, J. (1998). Basics of Qualitative Research: Procedures and Techniques for Developing Grounded Theory.

Strode, D. E., Huff, S. L., Hope, B., and Link, S. (2012). Coordination in co-located agile software development projects. Journal of Systems and Software, 85(6), 1222-1238.
Thomas, K. W. (1992). Conflict and conflict management: Reflections and update. Journal of Organizational Behavior, 13(3), 265-274.

Thulesius, H., Hakansson, A., and Petersson, K. (2003). Balancing: A basic process in end-of-life cancer care. Qualitative Health Research, 13(10), 1353-1377.

Turner, J. R. and Müller, R. (2004). Communication and co-operation on projects between the project owner as principal and the project manager as agent. European Management Journal, 22(3), 327-336.

Walczak, W. and Kuchta, D. (2013). Risks characteristic to Agile project management methodologies and responses to them. Operations Research and Decisions, 23.

Yetton, P., Martin, A., Sharma, R., and Johnston, K. (2000). A model of information systems development project performance. Information Systems Journal, 10(4), 263-289.

Zaheer, A., McEvily, B., and Perrone, V. (1998). Does trust matter? Exploring the effects of interorganizational and interpersonal trust on performance. Organization Science, 9(2), 141-159.

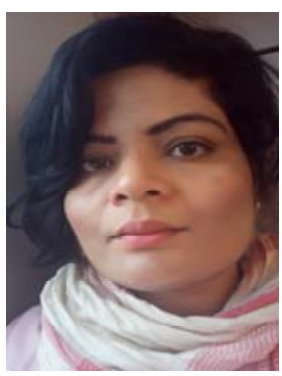

Lubna Siddique is studying for a $\mathrm{PhD}$ in agile software project management from the University of Oslo, Norway. Her research interests include working with agile methodologies, agile software project management, working within agile software teams and software process improvement.

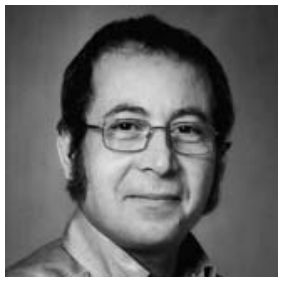

Bassam A. Hussein is an Associate Professor at the Norwegian University of Science and Technology (NTNU) Trondheim, Norway. His interests include application of gaming simulations, e-learning, requirements management, and organizational learning. He teaches project and requirements management and has been involved in the design, development, and implementation of a wide range of customized education programs in project management. 